\title{
Numerical investigation on the effect of labyrinth seal configuration on leakage
}

\author{
Tianlu Zhang ${ }^{1, a}$, Xi Zhang ${ }^{1}$, Xuemei Chen ${ }^{1}$ Yifan Jia ${ }^{1}$ \\ ${ }^{1}$ School of Mechanical Electronic \& Information Engineering, China University of Mining \& Technology (Beijing), Beijing 100083, P. R. China
}

\begin{abstract}
Labyrinth seals have been widely used in rotating machines. In this paper, labyrinth seals with rectangular tooth used in seawater pump with axial flow distribution were studied. The effects of structure parameters of labyrinth seals on sealing performance were numerically studied by the commercial computational fluid dynamics (CFD) software. The sealing length was considered as a constant, while the cavity width, cavity depth, tooth width and pressure ratio were varied. A large number of models were calculated to study the effects of various variables on leakage of labyrinth seals. Firstly, the results show that the effects of the cavity depth on leakage could be ignored compared with that of the cavity width and sealing length. Secondly, the optimal labyrinth seals with lowest leakage can be obtained with the appropriate values of cavity widths. Furthermore, for a certain pressure ratio, the optimal cavity widths resulting in the lowest leakage were demonstrated to be stable irrespective of the values of cavity depth and sealing length. Finally, increasing pressure ratio gives rise to an increase in the optimal cavity width. It reveals that the higher the pressure ratio is, the longer the cavity width is needed to reduce the leakage.
\end{abstract}

\section{Introduction}

Seawater pump is the key component of the SWRO (reverse osmosis seawater desalination) system $^{[1-3]}$. Seawater pump with axial flow distribution has the advantage of simplicity, reliability and tolerance. However, this structure has an inherent problem of leakage, which deteriorates the volumetric efficiency of the pump seriously ${ }^{[4]}$. The labyrinth seal featured by noncontacting structure has been widely used in rotating machines for dynamic seal over the years ${ }^{[5-8]}$. In marine environment, however, the labyrinth seal shows the benefits of low maintenance and reduced particulate contamination. Therefore, the labyrinth seal structures with rectangular cavities have been designed in seawater pump with axial flow distribution for reducing leakage.

For the labyrinth seal, both the shape and structural parameters of cavities have effects on leakage. For example, straight-through seals ${ }^{[6,8,9]}$, stepped seals ${ }^{[1,6,10]}$, honeycomb seals ${ }^{[10-13]}$, interlocking seals ${ }^{[1,14,15]}$ have different sealing performance. Furthermore, the structural parameters of cavities also influence the leakage of labyrinth seals, such as cavity width, cavity depth, cavity numbers and clearance size, etc. ${ }^{[1,13,16]}$. Actually, the sealing length is always fixed for a specific equipment. Therefore, it is significant to optimize the structure parameters of labyrinth seals considering the fixed sealing length.

In this paper, the effects of structure parameters of labyrinth seals on sealing performance were numerically studied by CFD software. To begin with, the sealing length was considered as a fixed value. Moreover, the cavity width, cavity depth, tooth width and pressure ratio were defined as a constant. Then, a large number of models were calculated to try to find the changing rules between the leakage and structure parameters of labyrinth seals. Finally, effects of these parameters on leakage were obtained, which is helpful to the design of labyrinth seals with low leakage.

\section{Method}

\subsection{Computational model}

Generally, increasing numbers of cavities can result in leakage reduction ${ }^{[10,17]}$. Thus, to exclude the effects of cavity numbers, the model with single cavity was performed, as shown in Fig. 1 (b). Wherein, the sealing length $L$ was set to be $3 \mathrm{~mm}, 5 \mathrm{~mm}, 10 \mathrm{~mm}$, respectively. The parameters of cavity width, cavity depth and clearance size were defined as $B, h$ and $c$, respectively. There was differential pressure between the input and output of labyrinth seals.

\subsection{Computational method}

The numerical study presented in this paper was conducted by CFD software. Water was chosen as the working fluid. The typically standard $k-\varepsilon$ model was used for turbulence. The pressure of the inlet and outlet was set to be 3 and 1 atmospheres, respectively. The effect of

${ }^{a}$ Corresponding author: zhangtianlu123@126.com 
grid density on simulation results was checked and then the total computational cells were set to be about $1 \times 10^{5}$.
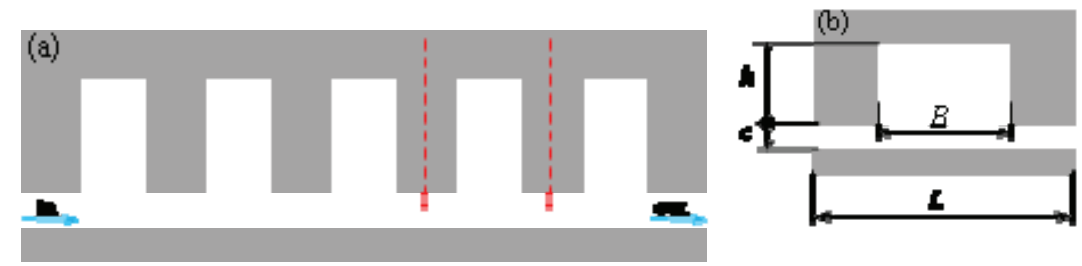

Figure 1. Labyrinth seal with rectangular structures, (a) the sketch of Labyrinth seal, (b) the model with single cavity, sealing length $L$, cavity width $B$, cavity depth $h$, clearance size $c$.

\section{Results and discussion}

Fig. 2 depicts the influences of the cavity depth, cavity width and sealing length on leakage of labyrinth seals. Firstly, it can be seen from Fig. 2 that the longer the sealing length is, the lower the leakage is in labyrinth seals. To be specific, labyrinth seals with the sealing length of $10 \mathrm{~mm}$ have a lower leakage than that with shorter sealing length of $5 \mathrm{~mm}$ and $3 \mathrm{~mm}$. Secondly, for a fixed sealing length, both the cavity width and depth have influences on the leakage of labyrinth seals. Obviously, the effect of changing cavity depth is smaller than that of cavity width and sealing length. As shown in Fig. 2, for the same value of $L$, the leakage Q is nearly equal with the different cavity depth, $h, 0.5 \mathrm{~mm}, 0.75 \mathrm{~mm}, 1.0 \mathrm{~mm}$ and $2 \mathrm{~mm}$, respectively. Finally, it is clearly seen that the leakage firstly decreases and then increases with the increasing of cavity width $B$. It is obvious that the lowest leakages could be obtained with the changing of cavity width $B$. It should be noted that all the labyrinth seal models with different parameters almost acquire their lowest leakage in the same value of $B$. In other words, the optimal labyrinth seal model with the lowest leakage can be found by the nearly constant value of $B$ irrespective of the values of cavity depth and sealing length. These results could contribute to the optimal design of labyrinth seals with rectangular structures.

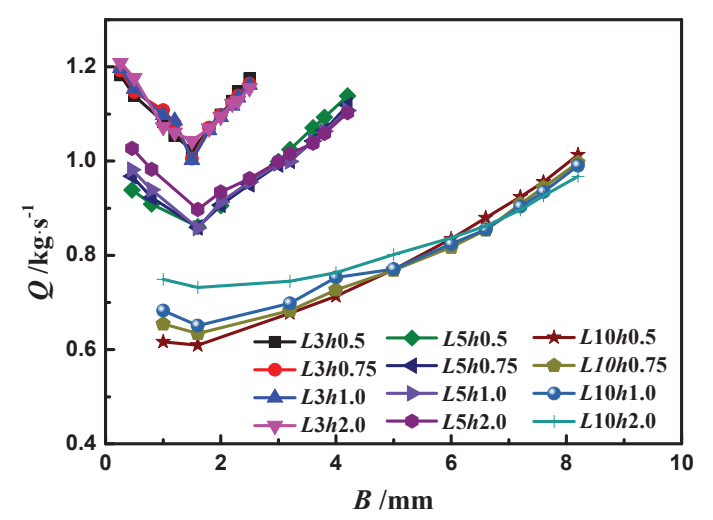

Figure 2. Effects of labyrinth seals structure parameters on leakage

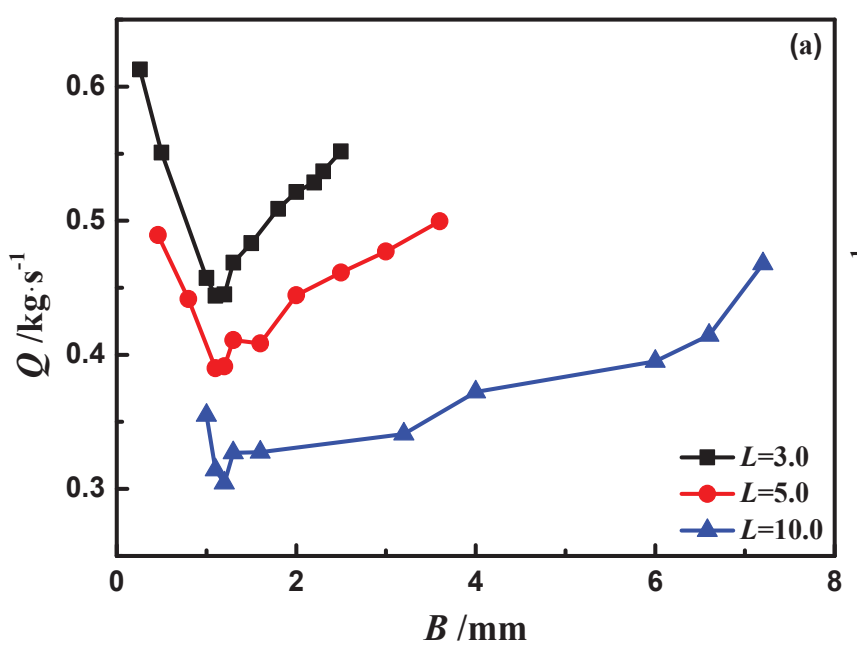

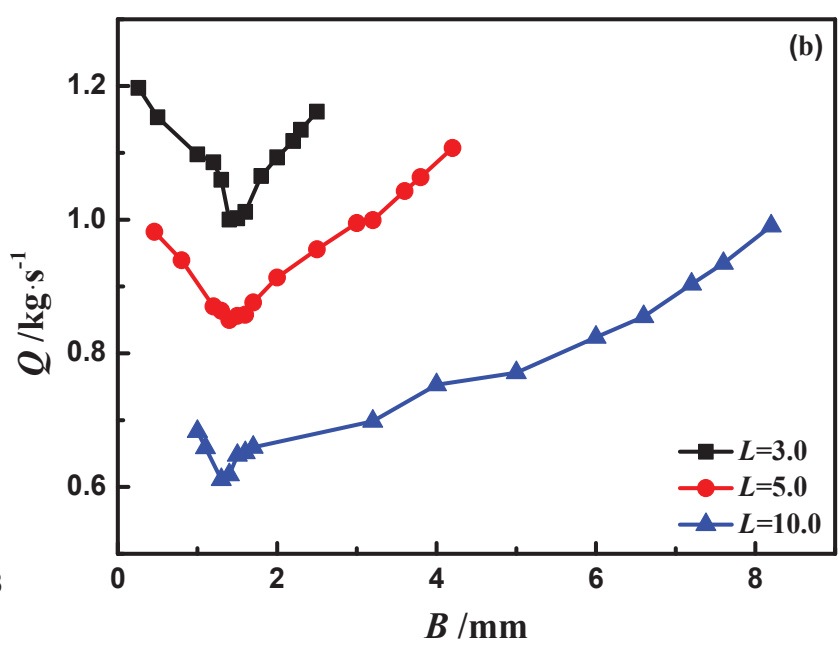



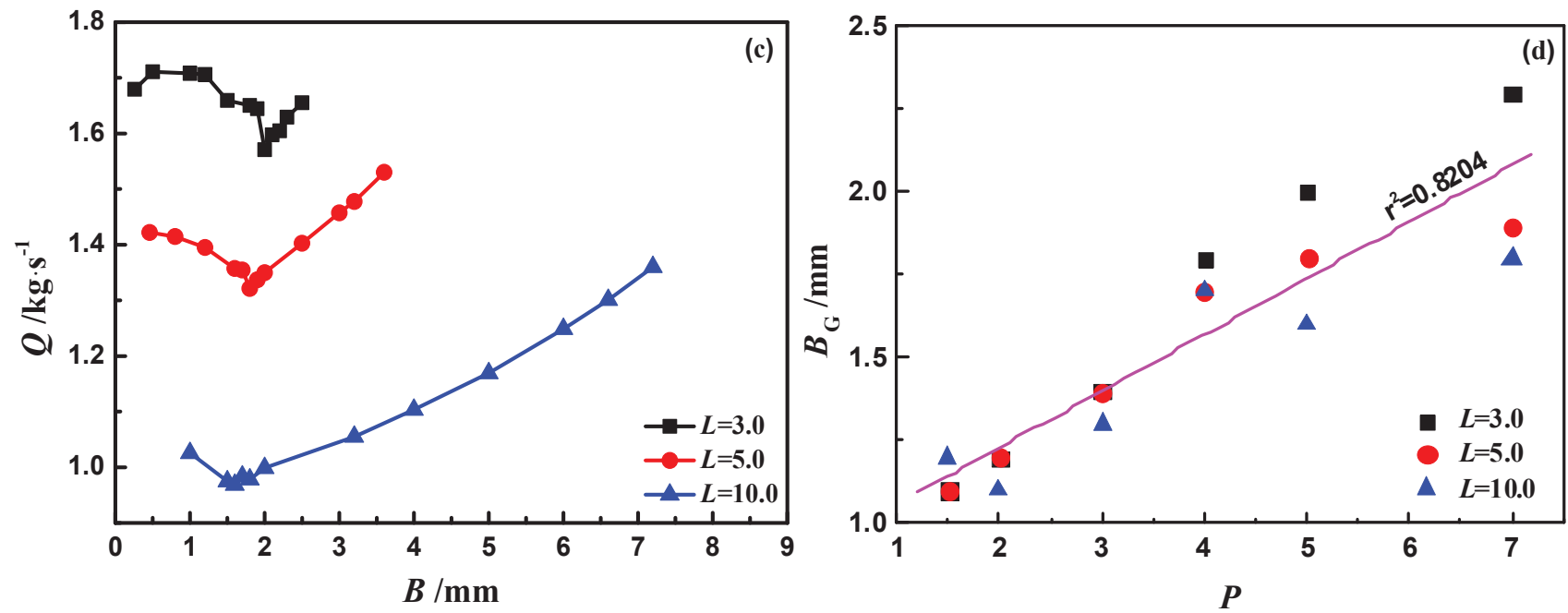

Figure 3. Effects of pressure ratios on optimal cavity width, (a) $h=1.0 \mathrm{~mm}, P=1.5$, (b) $h=1.0 \mathrm{~mm}, P=3.0$, (c) $h=1.0 \mathrm{~mm}, P=5.0$, (d) $h=1.0 \mathrm{~mm}$, various values of $P$.

The results show that the optimal labyrinth seal models were mainly decided by the cavity width has been obtained. The pressure ratio was another important factor which influences the leakage of labyrinth seals. Therefore, the value of cavity width $B$ for optimal labyrinth seal models in different pressure ratio situation was studied further. As shown in Fig.3, three different pressure ratio was considered with the value of $1.5,3.0$ and 5.0 and the results were shown in (a), (b) and (c), respectively. For the reason that cavity depths have small effect on leakage, models with the value of $1 \mathrm{~mm}$ for cavity depth were typically carried out. On one hand, it depicts that there are different values of $B$, where the leakage of labyrinth seals come to the lowest value, for various pressure ratio. On the other hand, the almost equal values of $B$ were obtained in a certain pressure ratio regardless of the values of sealing lengths. Finally, more values of pressure ratios were calculated to try to find the rule between pressure ratio and optimal cavity widths $B_{\mathrm{G}}$, where acquire the lowest leakage. Fig. 3 (d) reveals that increasing pressure ratio increases the value of optimal cavity width $B_{\mathrm{G}}$. It means that with the higher pressure ratio in actual conditions, longer cavity width is needed to reduce the leakage irrespective of the values of sealing length and cavity depth. Furthermore, the fitted curve was obtained to provide supports for more operating conditions, as followed equation:

$$
B_{G}=0.89+0.17 P \quad(1.5 \leq P \leq 7)
$$

\section{Conclusion}

In this paper, labyrinth seals with rectangular teeth were studied. Firstly, labyrinth seals with longer sealing length have lower leakages than that with shorter sealing lengths. Secondly, when the sealing length comes to a constant value, the effect of cavity width on leakage follows the trend that decreasing at first and then increasing. In addition, cavity depths have smaller influence on leakage than cavity width. Finally, the value of optimal cavity width resulting in the lowest leakage does not change over the cavity depth and sealing length, but changes over the pressure ratio. The increasing pressure ratio increases the value of optimal cavity width. It means that the higher pressure ratio is, the longer cavity width was needed to reduce the leakage irrespective of the value of sealing length and cavity depth. The results is valuable for the optimal design of rectangular labyrinth seals with low leakage adapt to the given operating conditions with various pressure ratios and sealing lengths.

\section{Acknowledgements}

The supports from the National Natural Science Foundation of China (Grant No. 51475197) are acknowledged.

\section{References}

1. Greenlee LF, Lawler DF, Freeman BD, Marrot B, Moulin P. Reverse osmosis desalination: water sources, technology, and today's challenges. Water research, 43, 2317-2348 (2009).

2. Fosselard G, Wangnick K. Comprehensive study on capital and operational expenditures for different types of seawater desalting plants $(\mathrm{RO}, \mathrm{MVC}, \mathrm{ME}$, ME-TVC, MSF) rated between $200 \mathrm{m3} / \mathrm{d}$ and 3,000 m3/d. Desalination, 76, 215-240 (1989).

3. Wang D, Li Z Y, Zhu Y Q. Lubrication and tribology in seawater hydraulic piston pump. Journal of Marine Science and Application, 2, 35-40(2003).

4. Jibin H, Yunfei Z, Xinjun Z, Shihua Y. Balancing characteristics of flow divider pintle in ball piston pump. Transactions of the Chinese Society of Agricultural Engineering, (2008).

5. WANG W Z, LIU Y Z, JIANG P N, CHEN H P. Numerical analysis of leakage flow through two labyrinth seals. Journal of Hydrodynamics, 19, $107-$ 112 (2007).

6. Kim TS, Cha KS. Comparative analysis of the influence of labyrinth seal configuration on leakage behavior. Journal of Mechanical Science and 
Technology, 23, 2830-2838 (2009).

7. Schramm V, Denecke J, Kim S, Wittig S. Shape optimization of a labyrinth seal applying the simulated annealing method. International Journal of Rotating Machinery, 10, 365-371 (2004).

8. Zhao W, Nielsen T, Billdal J. Effects of cavity on leakage loss in straight-through labyrinth seals. 25th IAHR Symposium on Hydraulic Machinery and Systems 2010 (2010).

9. Rhode DL, Adams RG. Rub-groove width and depth effects on flow predictions for straight-through labyrinth seals. Journal of Tribology, 126, 781-787 (2004).

10. Braun E, Dullenkopf K, Bauer H-J. Optimization of labyrinth seal performance combining experimental, numerical and data mining methods. Proceedings of ASME Turbo Expo, Copenhagen, Denmark (2012).

11. Chochua G, Shyy W, Moore J. Computational modeling for honeycomb-stator gas annular seal. International journal of heat and mass transfer, 45, 1849-1863 (2002).

12. Fr ̈̈ D, Bochon K. Influence of Honeycomb
Rubbing on the Labyrinth Seal Performance. Journal of Engineering for Gas Turbines and Power, 139, 012502 (2017).

13. Li J, Kong S, Yan X, Obi S, Feng Z. Numerical investigations on leakage performance of the rotating labyrinth honeycomb seal. Journal of Engineering for Gas Turbines and Power, 132, 062501 (2010).

14. Gao R, Kirk G. CFD study on stepped and drum balance labyrinth seal. Tribology Transactions, 56, 663-671 (2013).

15. Wang W, Liu Y, Meng G, Jiang P. Nonlinear analysis of orbital motion of a rotor subject to leakage air flow through an interlocking seal. Journal of Fluids and Structures, 25, 751-765 (2009).

16. Marsis E, Morrison G. Leakage and Rotordynamics Numerical Study of Circular Grooved and Rectangular Grooved Labyrinth Seals. Proceedings of ASME Turbo Expo 2013: Turbine Technical Conference and Exposition, San Antonio, Texas, USA, (2013). 